\title{
Study on the evaluation method and influencing factors of fracture conductivity of hydraulic fracturing support in shale reservoir
}

\author{
Yin Shun-li ${ }^{1}$, Zhuang Tian-lin ${ }^{1}$, Yang Li-yong ${ }^{1}$, Jia Yun-peng ${ }^{1}$, Liu Xue-wei ${ }^{1}$, Liu Yu ${ }^{1}$, Zhao Tao ${ }^{1}$ \\ 1 (PetroChina Dagang Oilfield Company, Tianjin, 300280, China) \\ Introduction:Yin Shun-li(1990-),Male, Master degree, Engineer,Mainly engaged in fracturing technology research. \\ Company:.Petroleum Engineering Research Institute of Dagang Oilfield, PetroChina
}

\begin{abstract}
The conductivity of supporting fractures is an important parameter to evaluate the hydraulic fracturing effect of shale reservoirs, and its size is affected by many factors.In this paper, the proppant is optimized and evaluated on the basis of real rock slab simulation and actual construction proppant test. The laboratory experimental study on the influence of proppant type, sand concentration, proppant embedding and fracturing fluid residue on propping fracture conductivity is carried out, the results show that the average conductivity of $40 / 70$ mesh proppant is about $7.15 \mathrm{~d} \cdot \mathrm{cm}$ at $5 \mathrm{~kg} / \mathrm{m}^{2}$ sand concentration under the condition of reservoir closure pressure of about $50 \mathrm{MPa}$, which can basically meet the requirements of main fracture conductivity of Kong 2 shale reservoir in Dagang Oilfield; the damage of guar gum fracturing fluid and proppant embedment are two important factors that cause the great decline of conductivity of rock slab, and the damage of guar gum fracturing fluid has a great influence on the conductivity, reaching about $50 \%$; the stronger the mud is (the higher the clay content is), the greater the embedment degree of proppant is, and the greater the loss of conductivity is;for the same lithology, the proppant particle size has little damage to the conductivity, and the sand concentration has a greater impact on the conductivity. The larger the sand concentration is, the smaller the loss of the conductivity is.
\end{abstract}

\section{Introduction}

Compared with conventional oil and gas reservoirs, tight shale gas reservoirs usually have the characteristics of low porosity, low permeability and low natural productivity. Therefore, it is necessary to use hydraulic fracturing to increase production in order to obtain industrial gas flow ${ }^{[1-3]}$. Through hydraulic fracturing, the reservoir matrix is "broken" to form network fractures and increase the volume of reservoir reconstruction. The conductivity of supporting fracture is an important parameter to evaluate the effect of hydraulic fracturing in shale reservoir, and its size is affected by many factors ${ }^{[4-7]}$.In order to maintain a good conductivity of fractures after the shale reservoir pressure, this paper evaluates the proppant by using the real rock plate simulation and the actual construction proppant to test the conductivity of the supporting fracture,laboratory experiments were carried out to study the effects of proppant type, sand concentration, proppant embedding and fracturing fluid residue on the conductivity of propped fractures.

\section{Self supporting fracture conductivity test}

In order to understand the conductivity of self-supporting fractures in Kong 2 shale oil reservoir without proppant, the core of well GD14 was used to prepare rock plate, and the fracture formed during fracturing was simulated by manual fracturing. The shear dislocation was $2.54 \mathrm{~mm}$ to form self-supporting fractures. The conductivity test was conducted with reference to the short-term conductivity test standard SY/T 6302-2019 of fracturing proppant filling layer ${ }^{[8]}$.

The self supporting fracture conductivity test is conducted by the fracturing acidizing conductivity test system developed by the laboratory. The principle of self supporting fracture conductivity test is Darcy law, as shown in Figure 1.After the self-supporting conductivity test, the test results of rock sample conductivity are shown in Figure 2.

$\overline{\text { *E-mail:dg_yinsli@petrochina.com.cn }}$ 


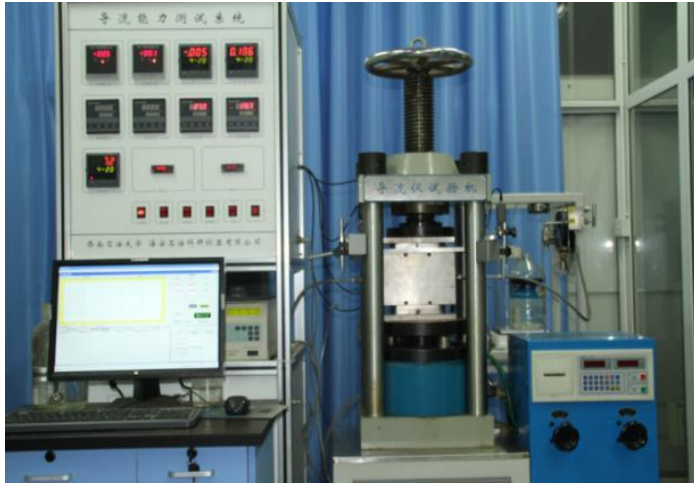

Fig. 1 Self supporting fracture conductivity test system

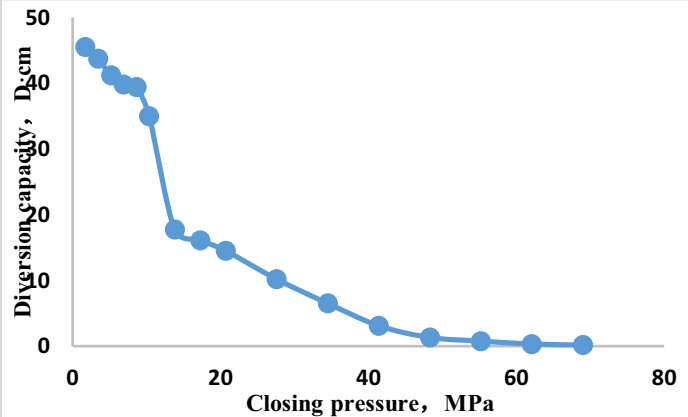

Fig. 2 Variation of self-supporting conductivity with closing stress

The conductivity of the self-supporting fracture decreases with the increase of closing stress, and the change process can be divided into three stages. In the first stage (the closure stress is less than 6.9MPa), when the closure stress is low, the conductivity of self-supporting fracture decreases with the increase of the closure stress, but the decrease is slow.In the second stage (the closure stress is between $6.9 \mathrm{MPa}$ and $13.8 \mathrm{MPa}$ ), the conductivity of self-supporting fracture decreases rapidly when the closure stress increases. In the third stage (the closure stress is greater than $13.8 \mathrm{MPa}$ ), the conductivity of self-supporting fracture decreases gradually with the increase of closure stress. When the closure pressure is $55.2 \mathrm{MPa}$, the conductivity of self-supporting fracture is still $0.77 \mathrm{~d} . \mathrm{cm}$, which meets the requirements of optimized conductivity of self-supporting micro fracture.But the self-supporting fracture can not meet the demand of conductivity of main fracture, so proppant should be added to meet the demand of reservoir stimulation.

\section{Test of short term conductivity of proppant}

Before testing the conductivity of proppant in the cracks of rock slab, it is necessary to know that proppant itself is not damaged by gel breaking fluid and the conductivity of proppant is not considered when it is embedded. Therefore, the short-term conductivity performance of proppant used in the process of rock slab testing is tested according to the short-term conductivity Test Standard
SY/T 6302-2019.The experimental scheme is shown in Table 1.

Tab. 1 Experimental scheme of conductivity test

\begin{tabular}{|c|c|c|c|}
\hline $\begin{array}{c}\text { Serial } \\
\text { number }\end{array}$ & $\begin{array}{c}\text { Test } \\
\text { medium }\end{array}$ & $\begin{array}{c}\text { Proppant } \\
\text { particle size, } \\
\text { mesh }\end{array}$ & $\begin{array}{c}\text { Sand } \\
\text { concentration, } \\
\mathrm{kg} / \mathrm{m}^{2}\end{array}$ \\
\hline 1 & $\begin{array}{c}\text { clean } \\
\text { water }\end{array}$ & $30 / 50$ & 5 \\
\hline 2 & $\begin{array}{c}\text { clean } \\
\text { water }\end{array}$ & $40 / 70$ & 5 \\
\hline
\end{tabular}

The test results show that the conductivity decreases with the increase of closure pressure, and the conductivity decreases exponentially with the increase of closure stress.As shown in Figure 3 and Figure 4.

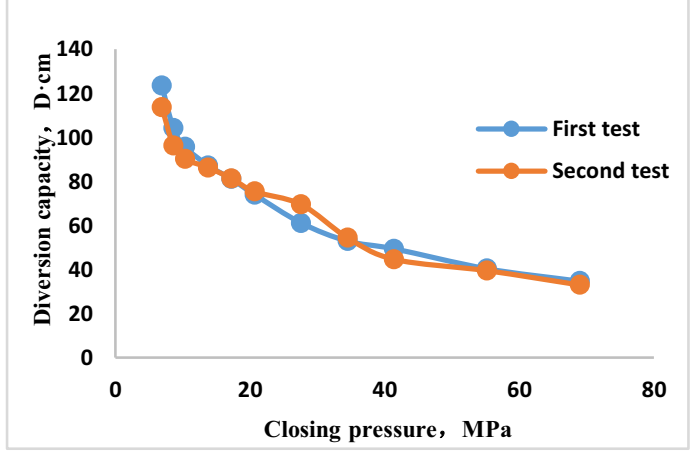

Fig. 3 Test curve of 30 / 50 mesh ceramsite conductivity

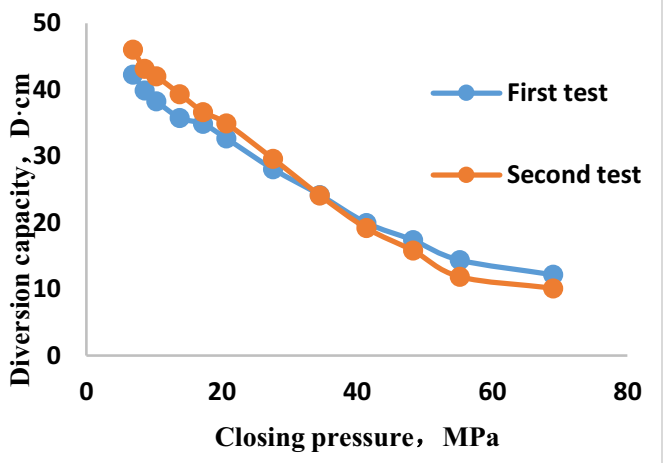

Fig. 4 Test curve of 40/70 mesh ceramsite conductivity

\section{Test and Analysis on conductivity of rock slab with sand}

This experiment simulates the conductivity of real formation fractures in Kong 2 formation of Dagang Oilfield, and tests the conductivity of supporting fractures by using field core, actual proppant, actual fracturing fluid and real formation pressure.

Shale oil reservoir fracturing adopts ceramsite with smaller particle size, and the designed maximum sand ratio and average sand ratio are low during fracturing operation. In order to understand the propping fracture conductivity under the condition of low sand ratio, the designed experimental scheme is shown in Table 2. 
Tab. 2 Experimental scheme for conductivity of propped fracture

\begin{tabular}{|c|c|c|c|c|}
\hline $\begin{array}{l}\text { Serial } \\
\text { number }\end{array}$ & $\begin{array}{l}\text { Sand concentration, } \\
\qquad \mathrm{kg} / \mathrm{m}^{2}\end{array}$ & $\begin{array}{c}\text { Particle size } \\
\text { mesh }\end{array}$ & Type of fluid & $\begin{array}{l}\text { Pretreatment } \\
\text { type }\end{array}$ \\
\hline 35 & 5 & $30 / 50$ & $\begin{array}{l}0.45 \% \text { gum guar+High anti } \\
\text { swelling }\end{array}$ & \multirow{8}{*}{$\begin{array}{c}\text { Low flow } \\
\text { displacement of } \\
\text { breaker for } 2 \\
\text { hours }\end{array}$} \\
\hline 39 & 5 & $30 / 50$ & $\begin{array}{c}0.45 \% \text { gum guar+Medium anti } \\
\text { swelling }\end{array}$ & \\
\hline 36 & 3 & $30 / 50$ & $\begin{array}{l}0.45 \% \text { gum guar+High anti } \\
\text { swelling }\end{array}$ & \\
\hline 42 & 3 & $30 / 50$ & $\begin{array}{l}0.4 \% \text { gum guar+Low anti } \\
\text { swelling }\end{array}$ & \\
\hline 40 & 5 & $40 / 70$ & $\begin{array}{c}0.4 \% \text { gum guar+Medium anti } \\
\text { swelling }\end{array}$ & \\
\hline 41 & 5 & $40 / 70$ & $\begin{array}{l}0.4 \% \text { gum guar+Low anti } \\
\text { swelling }\end{array}$ & \\
\hline 43 & 3 & $40 / 70$ & $\begin{array}{c}0.4 \% \text { gum guar+Medium anti } \\
\text { swelling }\end{array}$ & \\
\hline 38 & 3 & $40 / 70$ & $\begin{array}{c}0.45 \% \text { gum guar+Medium anti } \\
\text { swelling }\end{array}$ & \\
\hline
\end{tabular}

From $40 / 70$ mesh and 30/50 mesh proppant conductivity test results, the proppant fracture conductivity is greatly affected by the roughness of the fracture surface in the low closure pressure stage, and the guar gum concentration and anti swelling performance have little influence. But under the high closure pressure, the proppant conductivity is mainly affected by the sand concentration. As shown in Figure 5 and Figure 6.

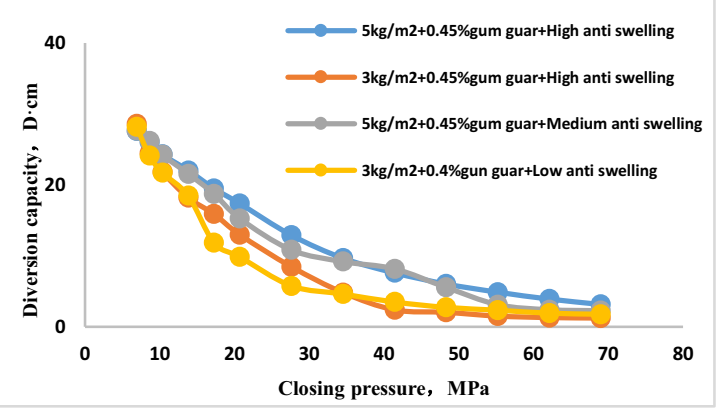

Fig. 5 Test results of fracture conductivity of 30/50 mesh

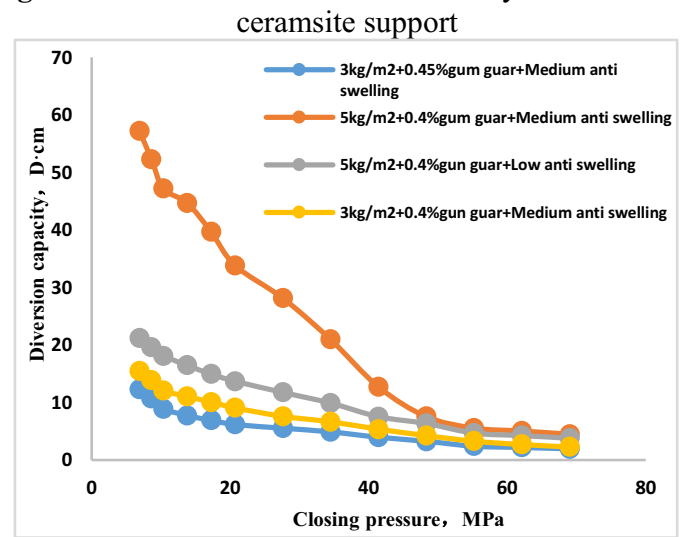

Fig. 6 Test results of fracture conductivity of 40/70 mesh ceramsite support

To sum up, the guar gum concentration and anti swelling performance in the fracturing fluid formula, as well as the particle size and sand concentration of proppant have a certain impact on its conductivity
${ }^{[9-11]}$.According to the experimental results, when the reservoir closure pressure is about $50 \mathrm{MPa}$, the average conductivity of $30 / 50$ mesh proppant at $5 \mathrm{~kg} / \mathrm{m}^{2}$ sand concentration is about $10.84 \mathrm{D} \cdot \mathrm{cm}$, the average conductivity at $3 \mathrm{~kg} / \mathrm{m}^{2}$ sand concentration is about $5.26 \mathrm{D} \cdot \mathrm{cm}$; the average conductivity of $40 / 70$ mesh proppant at $5 \mathrm{~kg} / \mathrm{m}^{2}$ sand concentration is about $7.15 \mathrm{D} \cdot \mathrm{cm}$ the average conductivity at $3 \mathrm{~kg} / \mathrm{m} 2$ sand concentration is $4.16 \mathrm{D} \cdot \mathrm{cm}$ about. Therefore, $40 / 70$ mesh can basically meet the requirements of main fracture conductivity of Kong 2 tight oil reservoir at $5 \mathrm{~kg} / \mathrm{m}^{2}$ sand concentration.

According to the optimization results of multi fracture conductivity in the early stage of Kong 2 shale oil reservoir ${ }^{[12]}$, the $40 / 70$ mesh proppant used in Kong 2 shale oil reservoir can meet the requirements of supporting fracture conductivity. Therefore, the amount of 40/70 mesh proppant should be optimized in fracturing design.

\section{Analysis of influencing factors of diversion capacity}

\subsection{Effect of fracturing fluid residue on conductivity}

After the proppant filling layer is damaged by the fracturing fluid, the proppant fracture conductivity will be greatly reduced. When the reservoir closure pressure is about $40 \mathrm{MPa}$, the damage of fracturing fluid to the conductivity is about $50 \%$, which indicates that the fracturing fluid residue has a great impact on the conductivity, as shown in Figure 7. 


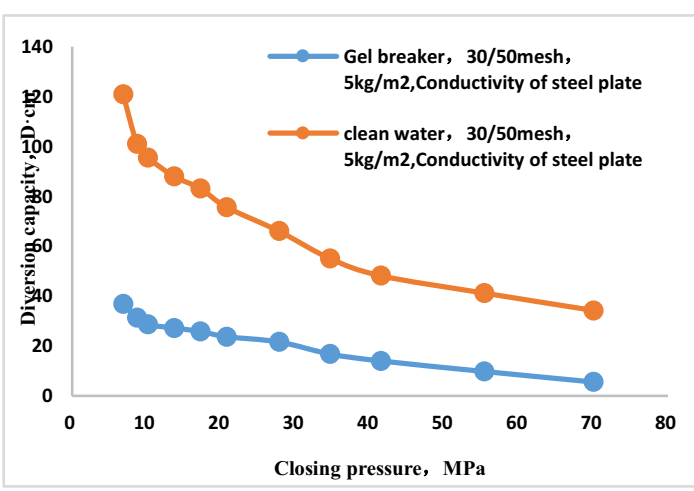

Fig. 7 Sand conductivity of 30/50 mesh ceramsite steel plate before and after fracturing fluid damage

\subsection{Effect of proppant embedment on conductivity}

In addition to the influence of fracturing fluid damage on proppant conductivity, the amount of proppant embedded in rock plate also has a certain influence on the conductivity. Therefore, the damage of proppant insertion is evaluated by completing the observation experiment of proppant embedding. The embedded depth of the test is analyzed by means of the ultra long focal length continuous zoom video microscope in the micro analysis room of the State Key Laboratory The results show that the depth and degree of the embedded rock plates are compared.As shown in Figure 8.

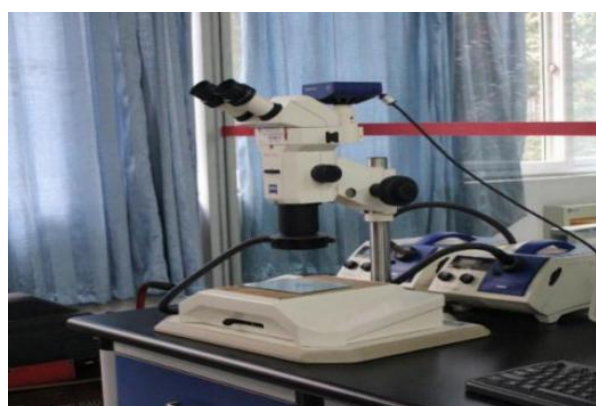

Fig. 8 Ziess STEMI SV 11 super long focal length continuous zoom video microscope

The embedding of proppant was observed and marked by ultra long focal length continuous zoom video microscope, as shown in Figure 9.

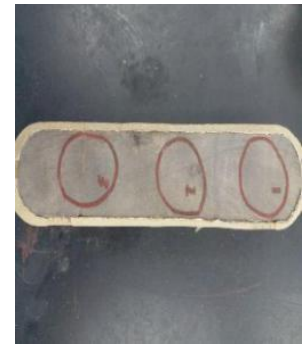

Overall drawing of rock slab

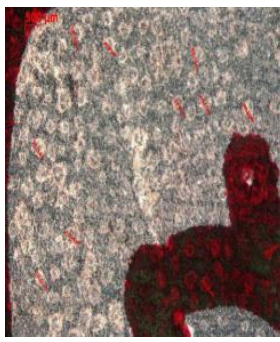

Area 2 Map

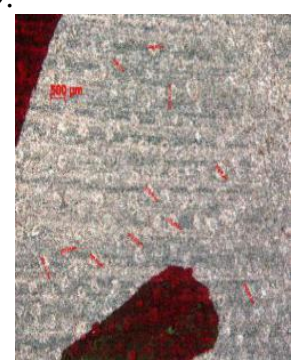

Area 1 Map

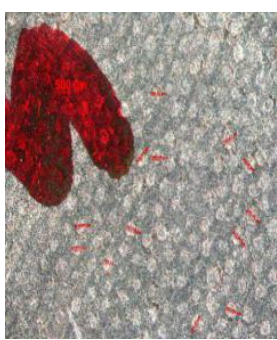

Area 3 Map

Fig.9 Observation and statistical chart of each area in the slab

According to the statistics and calculation of the points marked in the above figures, the embedded depth of each rock plate and the loss degree of conductivity are obtained, as shown in Table 3 .

Tab. 3 Proppant embedment depth and conductivity loss

\begin{tabular}{|c|c|c|c|c|c|c|c|}
\hline $\begin{array}{c}\text { Plate } \\
\text { number }\end{array}$ & Lithology & $\begin{array}{c}\text { Proppant } \\
\text { mesh }\end{array}$ & $\begin{array}{c}\text { concentra } \\
\text { tion } \\
\left(\mathrm{kg} / \mathrm{m}^{2}\right)\end{array}$ & $\begin{array}{c}\text { Average } \\
\text { particle size } \\
\text { of proppant } \\
(\mathrm{mm})\end{array}$ & $\begin{array}{c}\text { Embedment } \\
\text { depth of } \\
\text { proppant }(\mathrm{mm})\end{array}$ & $\begin{array}{c}\text { Seam width of } \\
\text { steel plate } \\
(\mathrm{mm})\end{array}$ & $\begin{array}{c}\text { Loss of } \\
\text { diversion } \\
\text { capacity } \\
(\%)\end{array}$ \\
\hline 35 & $\begin{array}{c}\text { Argillaceous } \\
\text { dolomite }\end{array}$ & $30 / 50$ & 5 & 0.3625 & 0.0922 & 0.7775 & 0.24 \\
\hline 36 & mudstone & $30 / 50$ & 3 & 0.3625 & 0.1138 & 0.4551 & 0.50 \\
\hline 38 & mudstone & $40 / 70$ & 3 & 0.312 & 0.0615 & 0.2345 & 0.52 \\
\hline 39 & mudstone & $30 / 50$ & 5 & 0.3625 & 0.0875 & 0.7775 & 0.23 \\
\hline 40 & $\begin{array}{c}\text { fine } \\
\text { sandstone }\end{array}$ & $40 / 70$ & 5 & 0.312 & 0.0187 & 0.62595 & 0.06 \\
\hline 41 & $\begin{array}{c}\text { fine } \\
\text { sandstone }\end{array}$ & $40 / 70$ & 5 & 0.312 & 0.0177 & 0.62595 & 0.06 \\
\hline 42 & $\begin{array}{c}\text { fine } \\
\text { sandstone }\end{array}$ & $30 / 50$ & 3 & 0.3625 & 0.0339 & 0.4551 & 0.15 \\
\hline 43 & $\begin{array}{c}\text { fine } \\
\text { sandstone }\end{array}$ & $40 / 70$ & 3 & 0.312 & 0.0173 & 0.2345 & 0.15 \\
\hline
\end{tabular}


The calculation results in Table 3 show that the stronger the argillaceous (the higher the clay content) is, the greater the embedding degree of proppant is, the greater the loss of conductivity is, as shown in Figure 10; for the same lithology, the proppant particle size has little damage to the conductivity, the sand concentration has a greater impact on the conductivity, and the greater the sand concentration is, the smaller the loss of conductivity is, as shown in Figure 11. Therefore, it is necessary to strengthen the anti swelling ability of rock and increase the sand concentration.

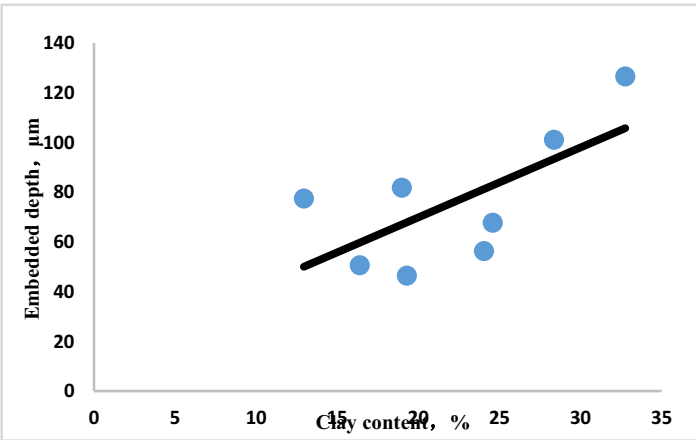

Fig. 10 Relationship between clay content and embedded depth

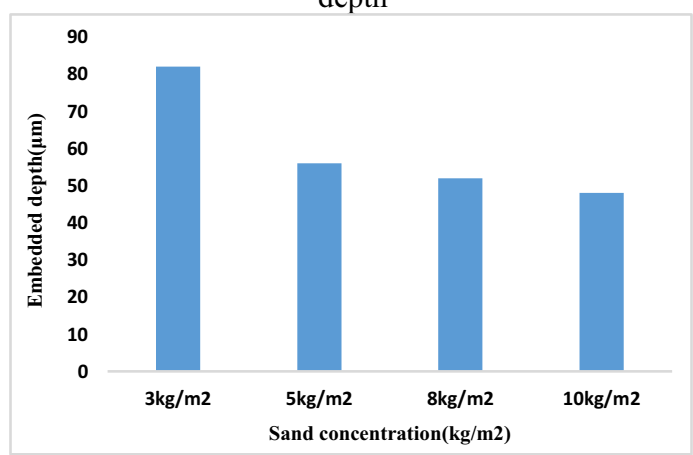

Fig. 11 Relationship between sand concentration and embedment depth

\section{Conclusion and understanding}

(1) According to the previous optimization results of the conductivity of the shale oil reservoir in kong 2, combined with this experiment, it shows that the average conductivity of $40 / 70$ mesh proppant at $5 \mathrm{~kg} / \mathrm{m}^{2}$ sand laying concentration is about $7.15 \mathrm{~d} \cdot \mathrm{cm}$ under the condition of reservoir closure pressure of about $50 \mathrm{MPa}$, which can basically meet the requirements of the main fracture conductivity of the shale oil reservoir in kong 2 .

( 2 ) Fracturing fluid damage and proppant embedment are two important factors that cause the conductivity of rock slab to decline greatly. Among them, fracturing fluid damage is greater, reaching about $50 \%$, which is inevitable for vegetable gum fracturing fluid. If we want to further improve the proppant fracture conductivity, we can consider appropriately reducing the amount of guar gum.

(3) The degree of proppant embedding has a great influence on the conductivity. To reduce the damage of proppant embedding, the fractured layer should choose the section with low clay content as far as possible. In the reservoir with high clay content, the amount of anti expansion agent should be increased as much as possible, and the sand laying concentration of proppant should be increased as much as possible in the main fracture.

\section{Reference}

1. Wang $\mathrm{Nu}$ Tao, Chen Zhong Liang, Zhu Ming Qian, et al. Analysis of production decline combination model of shale gas fractured horizontal wells $(\mathrm{J})$. Daqing Petroleum Geology and development, 2018, 37 (5): 138-143

2. Lei Yu, Zeng Yan, Ning Zhengfu. Unsteady seepage model and well test analysis of fractured horizontal wells in shale gas reservoir $(\mathrm{J})$. Fault block oil and gas fields, 2018, 25 (4): 73-79

3. Wang Haitao, jiangtingxue, Bian Xiaobing, et al. Optimization and field test of deep shale fracturing technology [J]. Petroleum drilling technology, 2016, 44 (2): 76-81

4. PARKER MA,MCDANIEL B W. Fracturing treatment design improved by conductivity measurements under in situ conditions [R] .SPE $16901,1987$.

5. LIUY,WANGM,SHIM,etal.Discussion on influencing factors of shale pores development $[\mathrm{J}]$. Acta Geologica Sinica, 2015, 89 (S1) : 61-62.

6. PALK, RAJASEKAR R, DONG J K, et al. Effect of fillers on natural rubber/high styrene rubber blends with nano silica: morphology and wear[J]. Materials \& Design, 2010, 31 (2) : 677-686.

7. State Energy Administration. SY/T 6302-2019 Test method for conductivity of fracturing proppant. Beijing: Petroleum Industry Press, 2019.

8. Zhu Yihui, Jia Changgui, Jiang tingxue. Calculation of shale propped fracture conductivity under the influence of multiple factors [J]. Acta petrologica Sinica, 2014, 36 (8): 129-132.

9. Bi Wentao, Lu Yongjun, Meng Chuanyou, et al. New research on Influencing Factors of shale reservoir conductivity $[\mathrm{J}]$. Science, technology and engineering, 2015, 15 (30): 115-118

10. Bi Wentao, Lu Yongjun, Meng Chuanyou, et al. Experimental study on fracture conductivity of shale reservoir ( J ). Fault block oil and gas fields, 2016, 23 (1): 133-136

11. Wang Lei, Wang Qi. Experimental study on conductivity of complex fractures in hydraulic fracturing of shale gas reservoir [J]. Journal of Xi'an University of Petroleum (NATURAL SCIENCE EDITION), 2017, 32 (3): 73-77

12. Tian Fuchun, Liu Xuewei, et al. Continuous sand fracturing technology for gliding water of continental shale oil in Dagang Oilfield [J]. Petroleum drilling technology, 2021:1-10 